\title{
Fluorescent Properties of ZnO Nanostructures Fabricated by Hydrothermal Method
}

\author{
Zhiwei Dong, ${ }^{1,2}$ Bing Han, ${ }^{3}$ Shixiong Qian, ${ }^{2}$ and Deying Chen ${ }^{1}$ \\ ${ }^{1}$ National Key Laboratory of Tunable Lasers, Institute of Optical-Electronics, Harbin Institute of Technology, \\ Harbin 150001, China \\ ${ }^{2}$ State Key Laboratory of Applied Surface Physics and Department of Physics, Fudan University, Shanghai 200433, China \\ ${ }^{3}$ College of Physics, Jilin University, Changchun 130001, China
}

Correspondence should be addressed to Zhiwei Dong, dong19809@163.com

Received 29 March 2011; Accepted 23 April 2011

Academic Editor: Ting Zhu

Copyright () 2012 Zhiwei Dong et al. This is an open access article distributed under the Creative Commons Attribution License, which permits unrestricted use, distribution, and reproduction in any medium, provided the original work is properly cited.

$\mathrm{ZnO}$ nanorods with mean diameter $200 \mathrm{~nm}$ on different substrates were fabricated by hydrothermal method. Fluorescent properties of fabricated $\mathrm{ZnO}$ nanorods were researched by both linear and nonlinear excitation using femtosecond lasers. The damage threshold of productions on Si substrate irradiated under intense femtosecond pulses was found much higher than that on $\mathrm{Zn}$ plate. Raman spectrum was also applied to investigate relative optical properties. The $\mathrm{A}_{1 L}$ optical mode was found to be important to the fluorescent properties of $\mathrm{ZnO}$ materials.

\section{Introduction}

$\mathrm{ZnO}$ is a kind of II-VI compound wide band gap semiconductor with a direct band gap of $3.37 \mathrm{eV}$ and a large exciton binding energy about $60 \mathrm{meV}$ at room temperature, which makes it a potential candidate for the room temperature ultraviolet (UV) laser diodes [1,2]. Researches on the fabrication of $\mathrm{ZnO}$ materials show that different kinds of nanostructures can be got through controlling fabrication methods or conditions [3-5]. Among the fabrication methods, hydrothermal has been found to be economical and flexible to realize various kinds of nanostructures such as nanorods and nanoflowers [6-9]. Most of the researches about hydrothermal fabrication were focused on the relationship between fabrication conditions and the configuration of the productions [10-13]. Special investigations on the effects of fabrication conditions on the optical properties of $\mathrm{ZnO}$ nanostructures are meaningful. But as far as we know, these researches are still few.

Besides, owing to the development of laser technology, the emergence of ultrafast laser, especially the femtosecond (fs) laser source with low repetition rate, makes it possible to get extremely intense field above $\mathrm{TW} / \mathrm{cm}^{2}$ which ensures us to explore the interaction between condensed matters and intense field. Recently, researches on the nonlinear excitation of $\mathrm{ZnO}$ with intense laser pulses have been done, and the nonlinear properties, especially the basic mechanisms of multiphoton absorption-induced fluorescent emission in $\mathrm{ZnO}$, are proven to be meaningful [14-20]. This calls for the $\mathrm{ZnO}$ materials with high quality that is stable under the intense field of ultrafast pulses [21]. However, most of the $\mathrm{ZnO}$ materials used in these experiments are fabricated by molecular beam epitaxy (MBE), metal-organic chemical vapor deposition (MOCVD), or magnetron sputtering [2225]. Special researches on the fluorescent properties of hydrothermal $\mathrm{ZnO}$ are quite few.

In this paper, we fabricated $\mathrm{ZnO}$ nanorods with mean diameter $200 \mathrm{~nm}$ on different substrates through hydrothermal at $90^{\circ} \mathrm{C}$. The fabrication conditions including the concentrations of reactants, $\mathrm{PH}$ value, and substrate properties on the fluorescent properties of the productions were discussed by applying Raman spectra and fluorescent spectra under linear and nonlinear excitation conditions.

\section{Experimental}

The details of the fabrication of $\mathrm{ZnO}$ materials are as follows. The Si or $\mathrm{Zn}$ plate substrates were first precleaned by 


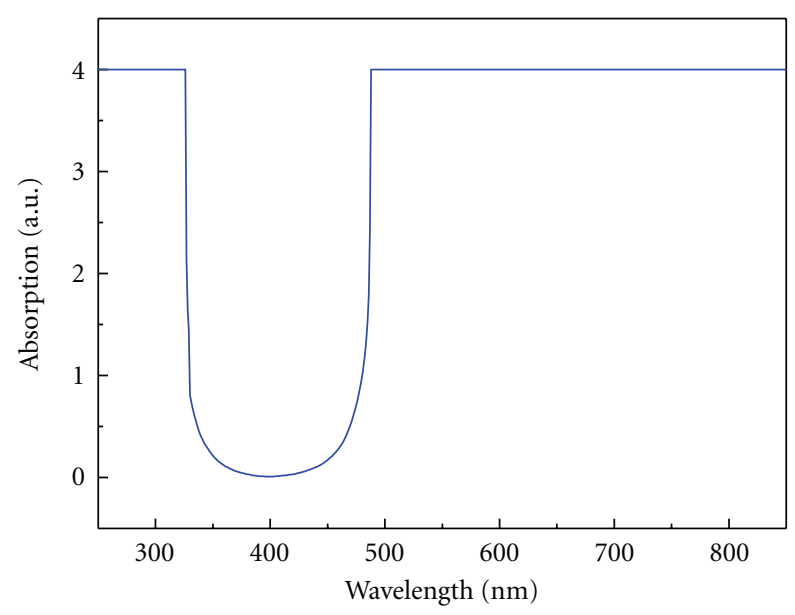

Figure 1: Absorption spectrum of the blue glass used in the measurement of fluorescent spectra under nonlinear excitation.

ultrasonic. Then, the reactant solution with zinc chloride solution $(0.1 \mathrm{M})$ and ammonia used to adjust the $\mathrm{PH}$ value were mixed, round, and poured into a Teflon vessel. After the substrates were put into it, the vessel was heated to $90^{\circ} \mathrm{C}$ for 4 hours and then cooled down naturally; the products were washed with deionized water for several times and dried. Scanning electron microscopy (SEM) was introduced to characterize the products. The main reactions occurred in the vessel can be expressed as follows [9]:

$$
\begin{aligned}
& \mathrm{Zn}^{2+}+4 \mathrm{NH}_{3} \cdot \mathrm{H}_{2} \mathrm{O} \longrightarrow \mathrm{Zn}\left(\mathrm{NH}_{3}\right)_{4}^{2+}+4 \mathrm{H}_{2} \mathrm{O} \\
& \mathrm{Zn}\left(\mathrm{NH}_{3}\right)_{4}^{2+}+2 \mathrm{OH}^{-} \longrightarrow \mathrm{ZnO}+4 \mathrm{NH}_{3} \uparrow+\mathrm{H}_{2}
\end{aligned}
$$

The fluorescent properties of fabricated nanostructures were recorded when the productions were excited by Xe lamp at $327 \mathrm{~nm}$. The nonlinear excitation laser source used in this experiment was a Ti:sapphire laser (Spectra-Physics, Spitfire) operating at repetition rate of $1 \mathrm{kHz}$ with output pulses centred around $800 \mathrm{~nm}$ and full width at half maximum of $150 \mathrm{fs}$. The nonlinear fluorescent spectra were recorded by a spectrometer with a blue glass placed in front to filter the excitation laser. The absorption spectrum of the blue glass is shown in Figure 1. The Raman spectra were recorded by a Raman spectrometer with an argon laser at $514.5 \mathrm{~nm}$ as the excitation source.

\section{Results and Discussion}

Figure 2(a) illustrates the products on the $\mathrm{Zn}$ plate when the content of the zinc chloride is $0.1 \mathrm{M}$ and $\mathrm{PH}$ value is 11 in the reactant solution. The productions show nanorods with the mean diameter about $200 \mathrm{~nm}$ from the SEM image. And they form balls with the size in micrometer. We investigated the effects of reactant solution by changing the content of zinc chloride or $\mathrm{PH}$ value. When the content of the zinc chloride decreased, the amount of the products decreased accordingly. Figure 2(b) shows the SEM image of the products when the content of the zinc chloride is $0.07 \mathrm{M}$. No nanostructures were found on the substrate. According to (1) and (2), when the concentration of zinc chloride is low, the reactions move to the left which means that $\mathrm{ZnO}$ cannot be formed in this condition.

The optical properties of the productions were first researched by fluorescent spectra under linear excitation. Figure 3 is the fluorescent spectra of fabricated nanostructures on $\mathrm{Zn}$ substrate with different $\mathrm{PH}$ values of the reactant solution excited at $327 \mathrm{~nm}$. The intense peak at near the ultraviolet region corresponds to the band-edge emission of $\mathrm{ZnO}$ which indicates that the nanostructures produced were $\mathrm{ZnO}$. Usually, there is a broad peak at around $550 \mathrm{~nm}$ in the fluorescent spectra of the hydrothermal fabricated $\mathrm{ZnO}$ material which is caused by defects induced in the fabrication process [26-29]. Compared with the UV emission, this peak is weak in the fluorescent spectra especially when the $\mathrm{PH}$ value of the reactant solution is 11 as shown in the blue line in Figure 3, implying good optical properties of the fabricated $\mathrm{ZnO}$ under this condition. When the $\mathrm{PH}$ value of the solution increased further, too much $\mathrm{OH}^{-}$in the reactant solution may cause defects in the $\mathrm{ZnO}$ which can be expressed as follows:

$$
\mathrm{ZnO}+2 \mathrm{OH}^{-} \longrightarrow\left(\mathrm{ZnO}_{2}\right)^{2-}+\mathrm{H}_{2} \mathrm{O}
$$

The fluorescent spectrum of the products fabricated under $\mathrm{PH}$ value of 12 on $\mathrm{Zn}$ plate is shown in the red dashed line in Figure 3. The broad peak around $550 \mathrm{~nm}$ enhances evidently which confirms the supposition above. The remaining $\left(\mathrm{ZnO}_{2}\right)^{2-}$ due to the incomplete cleaning step may also be another origin of this broad peak in the fluorescent spectra.

The fluorescent properties under nonlinear excitation conditions were investigated applying femtosecond pulses. The productions on $\mathrm{Zn}$ plate were found unstable under the intense excitation field, and no fluorescent spectrum was recorded under our experimental conditions. Figure 4 shows the fluorescent spectrum of the productions on $\mathrm{Si}$ plate irradiated under $800 \mathrm{~nm}$ femtosecond pulses. The peak at $400 \mathrm{~nm}$ was found moving together with the tuning of the excitation laser, and it kept locating at just half of the wavelength of the excitation laser. It was attributed to the second harmonic signal (SHG) of the excitation laser. The peak at the blue side of the SHG is the band-edge emission of $\mathrm{ZnO}$ which is mainly caused by the exciton-exciton collision or the recombination of the electron-hole plasma (EHP) [21]. This peak increased quite prominently compared with SHG, and the spectral width of this peak decreased to only $2 \mathrm{~nm}$ when the excitation intensity reached $0.2 \mathrm{TW} / \mathrm{cm}^{2}$, indicating that stimulated emission emerged under this excitation condition. This shows that we fabricated $\mathrm{ZnO}$ nanorods through hydrothermal with high quality that can realize stimulated emissions at room temperature under intense nonlinear excitation. The experimental results show that the damage threshold of $\mathrm{ZnO}$ nanorods irradiated under intense femtosecond pulses fabricated on $\mathrm{Si}$ substrate is much higher than that on $\mathrm{Zn}$ plate which is considered relative to the surface properties of the substrates for the surface 

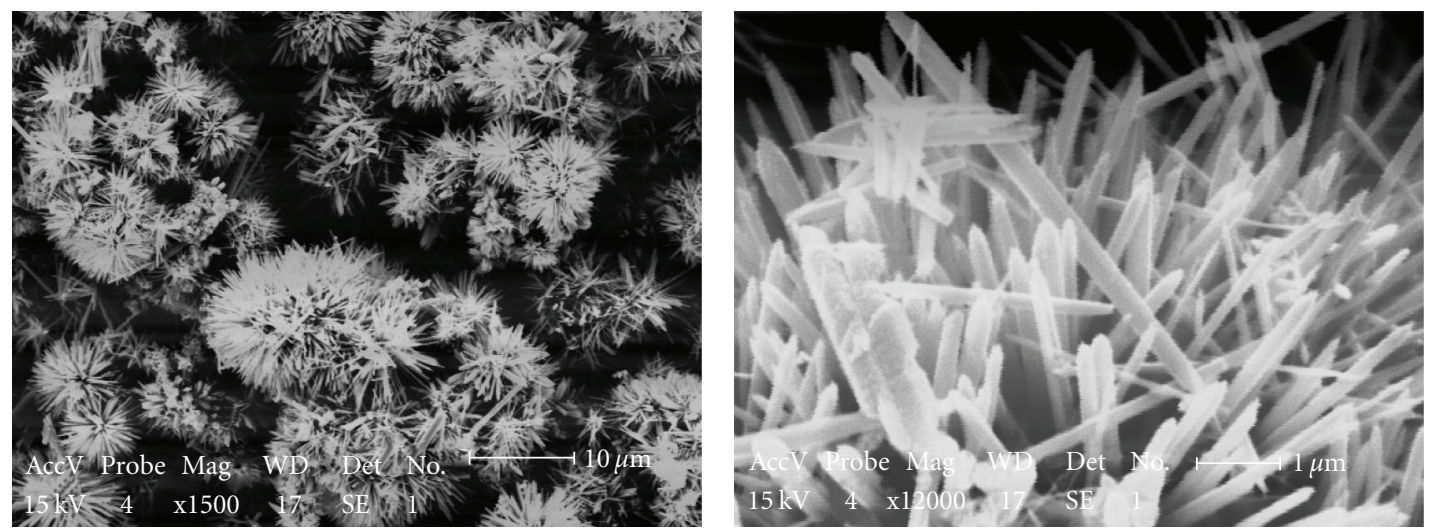

(a)

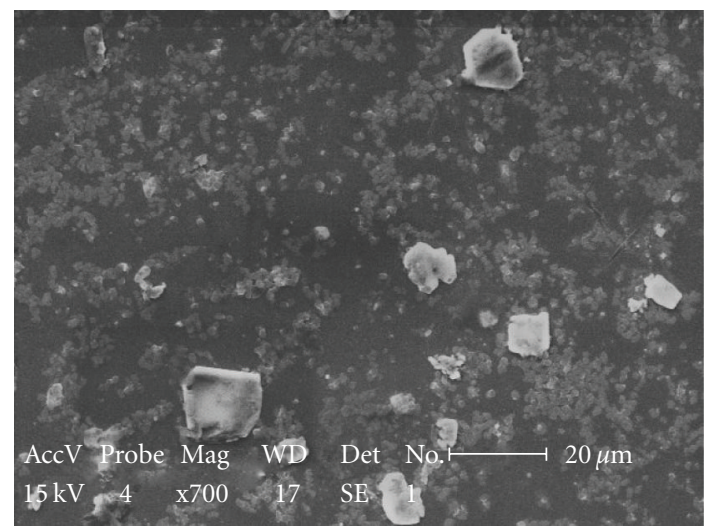

(b)

Figure 2: (a) SEM images of $\mathrm{ZnO}$ nanostructures on $\mathrm{Zn}$ substrate with different scales when the $\mathrm{Zn}^{2+}$ content is $0.1 \mathrm{M}$. (b) SEM image of fabricated $\mathrm{ZnO}$ on $\mathrm{Zn}$ substrate fabricated by hydrothermal method with low $\mathrm{Zn}^{2+}$ content $0.07 \mathrm{M}$.

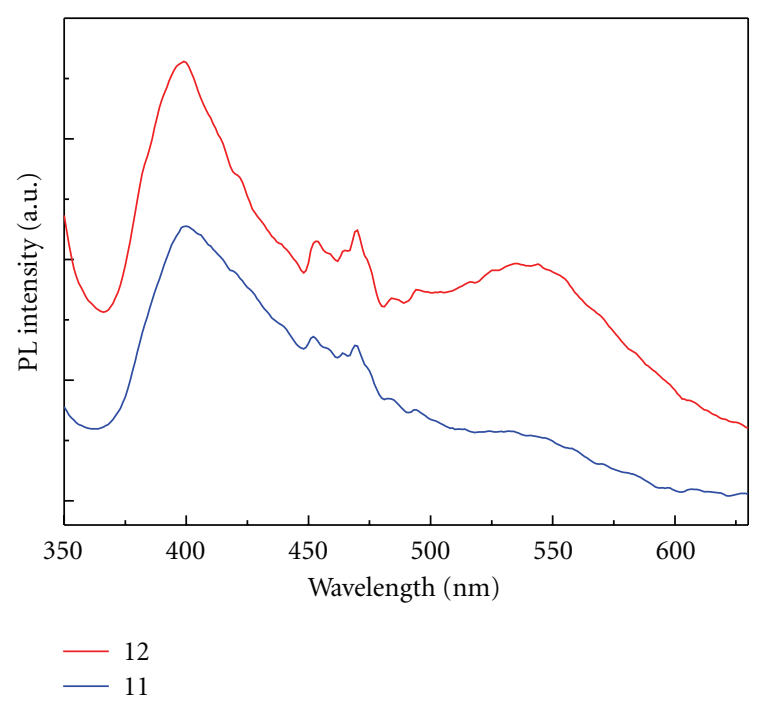

Figure 3: Fluorescent spectra of $\mathrm{ZnO}$ nanostructures fabricated with different $\mathrm{PH}$ values on $\mathrm{Zn}$ substrate excited at $327 \mathrm{~nm}$ (the red curve is moved upwards).

of the Si plate was much glazed than that of the $\mathrm{Zn}$ plate used in the experiment and the substrate softened when $\mathrm{Zn}$ is heated above $90^{\circ} \mathrm{C}$, because both $\mathrm{Si}$ and $\mathrm{ZnO}$ are cubic crystal structure, however, $\mathrm{Zn}$ is hexagonal crystal structure. The difference in their crystal structures is another reason that $\mathrm{Si}$ substrate benefits the formation of $\mathrm{ZnO}$ with high quality.

To further investigate the optical properties of $\mathrm{ZnO}$ on different substrates, we measured the Raman spectra of the $\mathrm{ZnO}$ nanostructures as shown in Figure 5 with the red and blue line responses to the result of products on $\mathrm{Si}$ and $\mathrm{Zn}$ plate, respectively. There are several Raman peaks in the region of $50-1400 \mathrm{~cm}^{-1}$. The obvious sharp peaks at 100 and $438 \mathrm{~cm}^{-1}$ correspond to $\mathrm{E}_{2}$ mode which confirm the formation of $\mathrm{ZnO}$, the wide peak around $1140 \mathrm{~cm}^{-1}$ is $A_{1}$ mode, while the relative weak peak at 331 and $378 \mathrm{~cm}^{-1}$ corresponds to $A_{1}$ and $A_{1 T}$ mode, respectively [30]. Compared with that on $\mathrm{Zn}$ substrate, the $\mathrm{A}_{1 \mathrm{~L}}$ mode which locates at $576 \mathrm{~cm}^{-1}$ only emerges in the case of $\mathrm{Si}$ as substrate. Considering the results under nonlinear excitation, we regard that the $A_{1 L}$ optical mode is important to the fluorescent properties of $\mathrm{ZnO}$ materials. Compared with transverse optical modes, the coupling between longitudinal optical modes and electromagnetic field is more efficient especially for loworder optical modes [31]. This is why $A_{1 L}$ optical mode is important to the fluorescent properties of productions. The experimental results show that Si substrate benefits the formation of $A_{1 L}$ optical mode compared with $\mathrm{Zn}$ plate. 


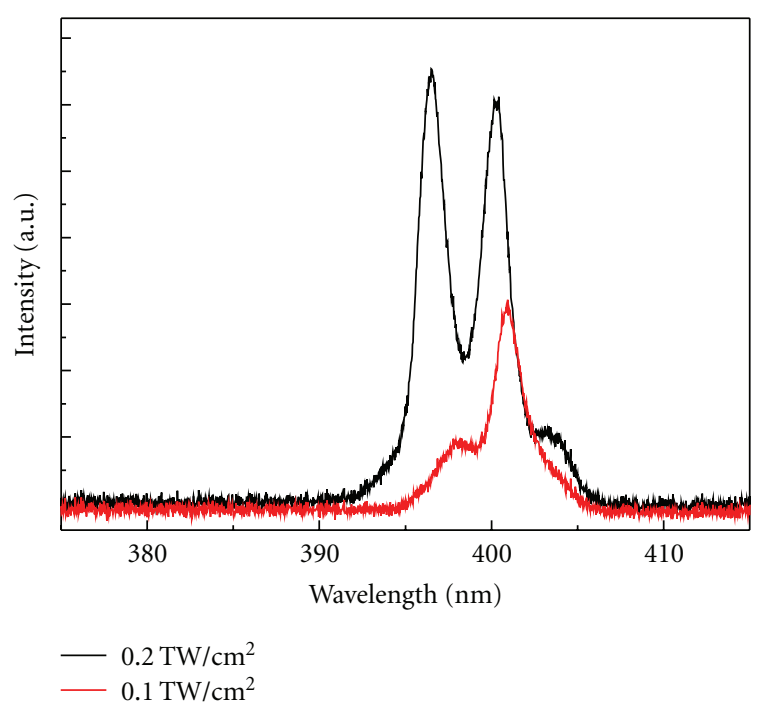

FIgURE 4: Fluorescent spectrum of fabricated $\mathrm{ZnO}$ nanostructure on Si substrate excited at $800 \mathrm{~nm}$ applying femtosecond pulses under different excitation intensities.

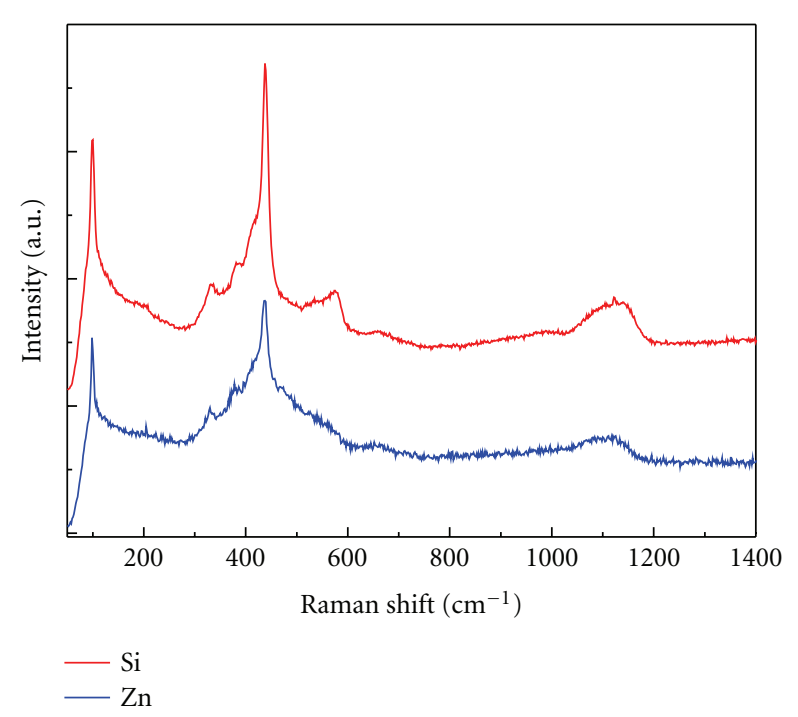

Figure 5: Raman spectra of fabricated $\mathrm{ZnO}$ nanostructures on $\mathrm{Si}$ and $\mathrm{Zn}$ substrates (the red curve is moved upwards).

\section{Conclusions}

In summary, $\mathrm{ZnO}$ nanorods have been fabricated by hydrothermal method on $\mathrm{Zn}$ and Si substrates. The effects of fabrication conditions including the concentrations of reactants, $\mathrm{PH}$ value, and substrates on the fluorescent properties of fabricated $\mathrm{ZnO}$ material have been researched. The optimized fabrication conditions were found, and stimulated emissions in the hydrothermal fabricated $\mathrm{ZnO}$ nanorods were realized at room temperature under intense nonlinear excitation. The $A_{1 L}$ optical mode was found important to the fluorescent properties of $\mathrm{ZnO}$ materials by analyzing the Raman spectra of the productions on $\mathrm{Si}$ and $\mathrm{Zn}$ substrates.

\section{Acknowledgments}

The authors gratefully acknowledge the financial support from National Natural Science Foundation of China (no. 11004042), the Research Fund for the Doctoral Program of Higher Education (RFDP20102302120022), China Postdoctoral Science Foundation (20090451006), Development Program for Outstanding Young Teachers in Harbin Institute of Technology (HITQNJS.2009.003), and relative foundation from Heilongjiang province and Harbin city (2011RFQXG003).

\section{References}

[1] M. H. Huang, S. Mao, H. Feick et al., "Room-temperature ultraviolet nanowire nanolasers," Science, vol. 292, no. 5523, pp. 1897-1899, 2001.

[2] P. Yu, Z. K. Tang, G. K. Wong et al., "Room-temperature gain spectra and lasing in microcrystalline $\mathrm{ZnO}$ thin films," Journal of Crystal Growth, vol. 184-185, pp. 601-604, 1998.

[3] L. Vayssieres, "Growth of arrayed nanorods and nanowires of $\mathrm{ZnO}$ from aqueous solutions," Advanced Materials, vol. 15, no. 5, pp. 464-466, 2003.

[4] A. Wei, C. X. Xu, X. W. Sun, W. Huang, and G. Q. Lo, "Field emission from hydrothermally grown $\mathrm{ZnO}$ nanoinjectors," Journal of Display Technology, vol. 4, no. 1, pp. 9-12, 2008.

[5] J. M. Szarko, J. K. Song, C. W. Blackledge et al., "Optical injection probing of single $\mathrm{ZnO}$ tetrapod lasers," Chemical Physics Letters, vol. 404, no. 1-3, pp. 171-176, 2005.

[6] H. Zhang, D. Yang, Y. J. Ji, X. Ma, J. Xu, and D. Que, "Low temperature synthesis of flowerlike $\mathrm{ZnO}$ nanostructures by cetyltrimethylammonium bromide-assisted hydrothermal process," Journal of Physical Chemistry B, vol. 108, no. 13, pp. 3955-3958, 2004.

[7] A. Wei, X. W. Sun, C. X. Xu, Z. L. Dong, M. B. Yu, and W. Huang, "Stable field emission from hydrothermally grown ZnO nanotubes," Applied Physics Letters, vol. 88, no. 21, Article ID 213102, 2006.

[8] C. X. Xu, A. Wei, X. W. Sun, and Z. L. Dong, "Aligned ZnO nanorods synthesized by a simple hydrothermal reaction," Journal of Physics D, vol. 39, no. 8, pp. 1690-1693, 2006.

[9] A. Wei, X. W. Sun, C. X. Xu et al., "Growth mechanism of tubular $\mathrm{ZnO}$ formed in aqueous solution," Nanotechnology, vol. 17, no. 6, pp. 1740-1744, 2006.

[10] H. D. Li, S. F. Yu, S. P. Lau et al., "High-temperature lasing characteristics of $\mathrm{ZnO}$ epilayers," Advanced Materials, vol. 18, no. 6, pp. 771-774, 2006.

[11] H. Cao, J. Y. Wu, H. C. Ong, J. Y. Dai, and R. P. H. Chang, "Second harmonic generation in laser ablated zinc oxide thin films," Applied Physics Letters, vol. 73, no. 5, pp. 572-574, 1998.

[12] G. I. Petrov, V. Shcheslavskiy, V. V. Yakovlev, I. Ozerov, E. Chelnokov, and W. Marine, "Efficient third-harmonic generation in a thin nanocrystalline film of $\mathrm{ZnO}$," Applied Physics Letters, vol. 83, no. 19, pp. 3993-3995, 2003.

[13] X. Zhang, H. Fang, S. Tang, and W. Ji, "Determination of twophoton-generated free-carrier lifetime in semiconductors by a single-beam Z-scan technique," Applied Physics B, vol. 65, no. 4-5, pp. 549-554, 1997.

[14] E. V. Chelnokov, N. Bityurin, I. Ozerov, and W. Marine, "Two-photon pumped random laser in nanocrystalline $\mathrm{ZnO}$," Applied Physics Letters, vol. 89, no. 17, Article ID 171119, 2006. 
[15] Y. F. Zhang, R. E. Russo, and S. S. Mao, "Femtosecond laser assisted growth of $\mathrm{ZnO}$ nanowires," Applied Physics Letters, vol. 87, no. 13, Article ID 133115, 3 pages, 2005.

[16] D. Li, Y. H. Leung, A. B. Djurišić et al., "Different origins of visible luminescence in $\mathrm{ZnO}$ nanostructures fabricated by the chemical and evaporation methods," Applied Physics Letters, vol. 85, no. 9, pp. 1601-1603, 2004.

[17] W. Z. Xu, Z. Z. Ye, D. W. Ma et al., "Quasi-aligned ZnO nanotubes grown on Si substrates," Applied Physics Letters, vol. 87, no. 9, Article ID 093110, 3 pages, 2005.

[18] I. H. Lee, K. J. Yee, K. G. Lee, E. Oh, D. S. Kim, and Y. S. Lim, "Coherent optical phonon mode oscillations in wurtzite $\mathrm{ZnO}$ excited by femtosecond pulses," Journal of Applied Physics, vol. 93, no. 8, pp. 4939-4941, 2003.

[19] R. Prasanth, L. K. Van Vugt, D. A. Vanmaekelbergh, and H. C. Gerritsen, "Resonance enhancement of optical second harmonic generation in a $\mathrm{ZnO}$ nanowire," Applied Physics Letters, vol. 88, no. 18, Article ID 181501, 2006.

[20] C. F. Zhang, Z. W. Dong, G. J. You et al., "Observation of twophoton-induced photoluminescence in $\mathrm{ZnO}$ microtubes," Applied Physics Letters, vol. 87, no. 5, Article ID 051920, 2005.

[21] Z. W. Dong, C. F. Zhang, K. J. Liu, Y. L. Yan, H. Deng, and S. X. Qian, "Multi-photon excitation in ZnO materials," Frontiers of Physics in China, vol. 3, no. 2, pp. 181-190, 2008.

[22] P. Fons, K. Iwata, S. Niki, A. Yamada, and K. Matsubara, "Growth of high-quality epitaxial $\mathrm{ZnO}$ films on alpha- $\mathrm{Al}_{2} \mathrm{O}_{3}$," Journal of Crystal Growth, vol. 201, pp. 627-632, 1999.

[23] J. H. Lin, Y. J. Chen, H. Y. Lin, and W. F. Hsieh, “Two-photon resonance assisted huge nonlinear refraction and absorption in ZnO thin films," Journal of Applied Physics, vol. 97, no. 3, Article ID 033526, 2005.

[24] Y. Liu, C. R. Gorla, S. Liang et al., "Ultraviolet detectors based on epitaxial $\mathrm{ZnO}$ films grown by MOCVD," Journal of Electronic Materials, vol. 29, no. 1, pp. 69-74, 2000.

[25] K. K. Kim, J. H. Song, H. J. Jung, W. K. Choi, S. J. Park, and J. H. Song, "The grain size effects on the photoluminescence of $\mathrm{ZnO} /$ alpha $\mathrm{Al}_{2} \mathrm{O}_{3}$ grown by radio-frequency magnetron sputtering," Journal of Applied Physics, vol. 87, no. 7, pp. 35733575, 2000.

[26] K. K. Kim, J. H. Song, H. J. Jung et al., "Photoluminescence and heteroepitaxy of $\mathrm{ZnO}$ on sapphire substrate (0001) grown by rf magnetron sputtering," Journal of Vacuum Science and Technology A, vol. 18, no. 6, pp. 2864-2868, 2000.

[27] J. B. Liang, J. W. Liu, Q. Xie, S. Bai, W. Yu, and Y. Qian, "Hydrothermal growth and optical properties of doughnutshaped ZnO microparticles," Journal of Physical Chemistry B, vol. 109, no. 19, pp. 9463-9467, 2005.

[28] J. J. Wu, H. I. Wen, C. H. Tseng, and S. C. Liu, "Wellaligned $\mathrm{ZnO}$ nanorods via hydrogen treatment of $\mathrm{ZnO}$ films," Advanced Functional Materials, vol. 14, no. 8, pp. 806-810, 2004.

[29] F. S. Wen, W. L. Li, J. H. Moon, and J. H. Kim, "Hydrothermal synthesis of $\mathrm{ZnO}$ : $\mathrm{Zn}$ with green emission at low temperature with reduction process," Solid State Communications, vol. 135, no. 1-2, pp. 34-37, 2005.

[30] R. P. Wang, G. Xu, and P. Jin, "Size dependence of electronphonon coupling in ZnO nanowires," Physical Review B, vol. 69, no. 11, Article ID 113303, 2004.

[31] T. L. Phan, R. Vincent, D. Cherns, N. H. Dan, and S. C. Yu, "Enhancement of multiple-phonon resonant Raman scattering in Co-doped $\mathrm{ZnO}$ nanorods," Applied Physics Letters, vol. 93, no. 8, Article ID 082110, 2008. 

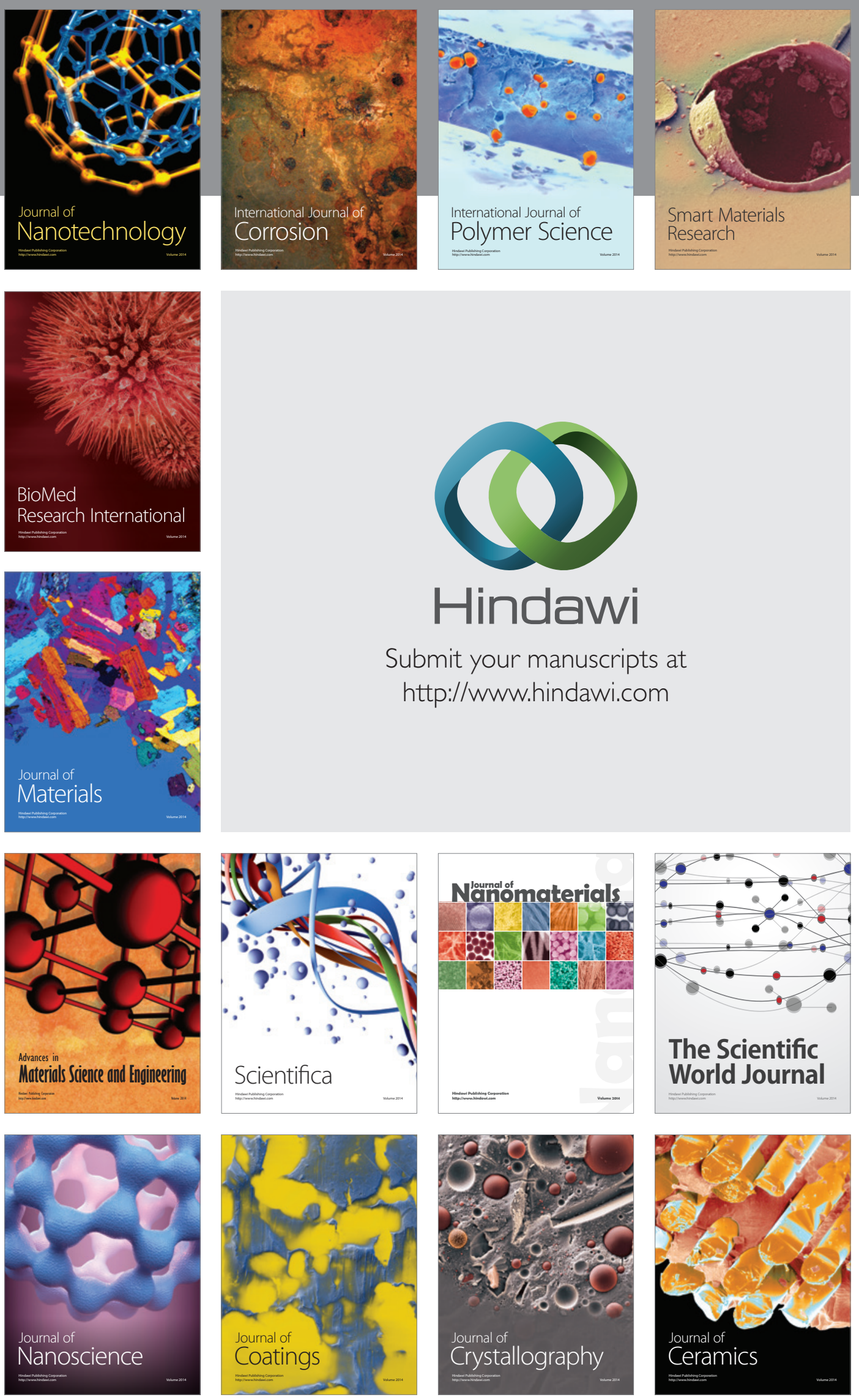

The Scientific World Journal

Submit your manuscripts at

http://www.hindawi.com

\section{World Journal}

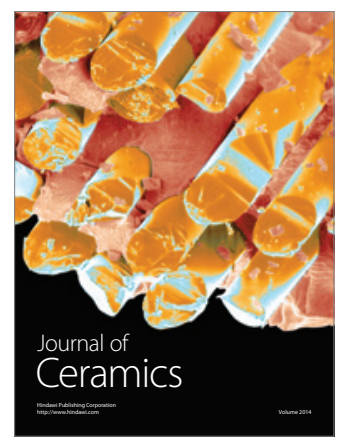

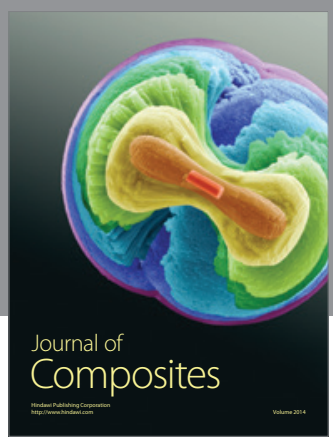
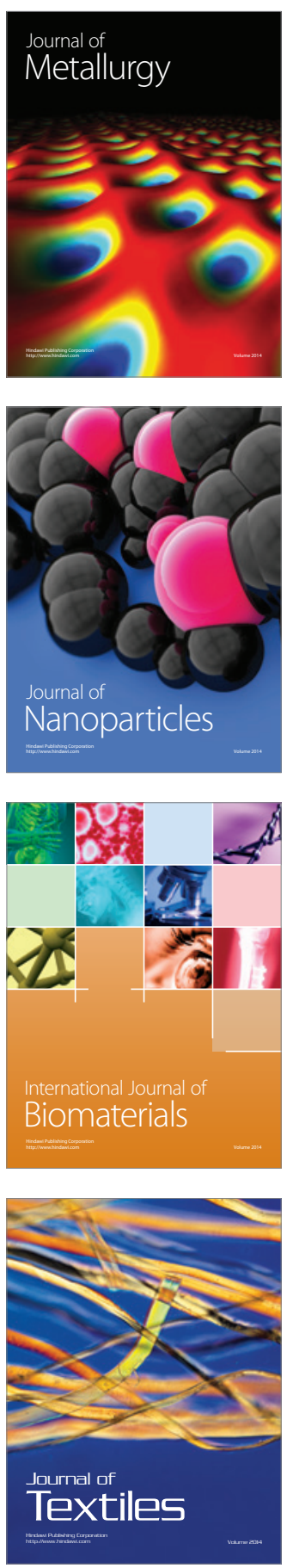